\title{
A PORTA DA AMAZÔNIA É AQUI! DESENVOLVIMENTO E EDUCAÇÃO NO GOVERNO DE JOSÉ SARNEY NO MARANHÃO $(1966-1970)$
}

\author{
Elizânia Sousa do Nascimento ${ }^{1}$
}

\begin{abstract}
Resumo: A chegada de José Sarney ao governo do Maranhão em 1966 foi impulsionada, entre outras estratégias, por uma rede discursiva que possuía no desenvolvimento seu ponto central de apoio. Entre os campos que deveriam não apenas estimular, mas também sustentar o desenvolvimento do Estado, encontrava-se a educação. $\mathrm{O}$ artigo apresenta os projetos que foram constituídos pelo Programa de governo do Maranhão Novo para os níveis primário e secundário: O Projeto João de Barro, a Televisão Educativa do Maranhão - TVE/MA e o Projeto Bandeirante. Destaca-se a rede discursiva que gravitava em torno desses projetos e analisa-se as correspondências entre esses discursos e a efetividade dos projetos.
\end{abstract}

Palavras-chave: Desenvolvimento. Maranhão 66. Projeto João de Barro. TVE/MA. Projeto Bandeirante.

\section{AMAZON DOOR IS HERE! DEVELOPMENT AND EDUCATION UNDER JOSÉ SARNEY'S STATE ADMINISTRATION OF MARANHÃO (1966 - 1970)}

Abstract: The beginning of José Sarney's state administration of Maranhão in 1966 was promoted, among other strategies, by a discursive net that had the idea of development as its central supporting point. Among the fields that should not only boost, but also support the development of the State, was education. This article presents the projects that were constituted by the Maranhão Novo government program for the primary and secondary levels: The João de Barro Project, the Televisão Educativa do Maranhão (TVE/MA) and the Bandeirante Project. The discursive net that gravitated around these projects and the relationships between them and the effectiveness of the projects are analyzed.

Keywords: Development. Maranhão 66. João de Barro Project. TVE/MA. Bandeirante Project.

\section{¡LA PUERTA DE LA AMAZONIA ESTÁ AQUÍ! DESARROLLO Y EDUCACIÓN EN EL GOBIERNO DE JOSÉ SARNEY EN MARANHÃO (1966 - 1970)}

Resumen: La llegada de José Sarney al gobierno de Maranhão en 1966 fue impulsada, entre otras estrategias, por una red discursiva que tenía el desarrollo como punto central de apoyo. Entre los campos que no solo debían impulsar, sino también apoyar el desarrollo del Estado, estaba la educación. El artículo presenta los proyectos que fueron constituidos por el programa de gobierno de Maranhão Novo para los niveles primario y secundario: Proyecto João de Barro, Televisão Educativa do Maranhão - TVE / MA y Proyecto Bandeirante. Se destaca la trama discursiva que gravitó en torno a estos proyectos y se analizan las correspondencias entre estos discursos y la efectividad de los proyectos.

\footnotetext{
${ }^{1}$ Professora Assistente I da Universidade Estadual da Região Tocantina do Maranhão (UEMASUL). É Mestra em Educação pela Universidade Federal do Piauí (2013). Graduada em Pedagogia pela Universidade Federal do Maranhão (2005). É coordenadora do Núcleo de Estudos em Políticas e História da Educação - NEPHE / UEMASUL (2016). Atualmente cursa o Doutorado na Universidade de São Paulo - FEUSP e desenvolve pesquisas sobre internatos religiosos no interior do Maranhão entre as décadas de 1950 a 1970, sob a orientação da Profa. Dra. Marta Maria Chagas de Carvalho.
} 
DOI: 10.47694/issn.2674-7758.v3.i7.2021.102123

Palabras clave: Desarrollo. Maranhão 66. Proyecto João de Barro. TVE / MA. Proyecto Bandeirante.

\section{Introdução}

Em 1965, José Sarney foi eleito governador do Maranhão, apoiado em uma rede discursiva que apregoava o renascer de um tempo próspero e de desenvolvimento para o Estado. Seus discursos giravam em torno da tônica de oposição "[...] ao Governo que é arcaico, ao Governo que é marasmo, ao Governo que é ganância", dizia o governador: “[...] queremos um Maranhão novo, um Maranhão mais rico, um Maranhão melhor". (SARNEY, 1970, p.46).

Do período político anterior, conhecido como "Vitorinismo", José Sarney realçava um cenário onde tudo era desalentador: "Sem portos, sem estradas, sem energia, sem escolas, sem hospitais e sem administração, ninguém pensava em riquezas nem acreditava em progresso. Era o desencanto.” (SARNEY, 1970, p.119). Sua eleição, apoiada pela Ditadura Militar instaurada no Brasil a partir de 1964, era apresentada por ele como simultânea à extinção da oligarquia política de Vitorino Freire no Maranhão: "Fui eleito pelo povo. Meu mandato trouxe a marca da luta e só foi possível graças à moralização eleitoral, às garantias surgidas e à liquidação da oligarquia política, obra, como tantas afirmei, da Revolução que eu apoiei e por ela fui apoiado." (JORNAL DO DIA, 1968, p.1 - grifos nossos).

No campo educacional, sobre os ensinos médio e superior, o governador fazia comparações com outros estados da federação: "A educação média e superior são permitidas a faixas ínfimas da juventude: apenas 1 em 200 habitantes chega ao ensino médio, contra 1 em 50 no Pará, 1 em 80 no Goiás e 1 em 100 no Piauí” (SARNEY, 1970, p.13). Sobre o ensino primário, denunciava, em 1967: “O índice de escolarização no grau elementar não ultrapassava os 35\% [...]”. Nas palavras de Sarney, tais realidades numéricas encontravam-se "[...] entre os mais sérios impedimentos que obstaculizavam a marcha do Maranhão para o desenvolvimento [...]”. (MARANHÃO, 1967).

\footnotetext{
${ }^{2}$ Referência ao período da história maranhense dominada politicamente pelo Senador pernambucano, Vitorino Freire, de quem Sarney pretendia demarcar descontinuidade político-administrativa.
} 
DOI: 10.47694/issn.2674-7758.v3.i7.2021.102123

Como que num jogo de luz e sombras, José Sarney apresentava a superação, em apenas um ano de sua gestão, do marasmo em que o campo educacional do Estado estivera imerso até então:

No curto prazo de que dispunha um Governo apenas instalado, a 31 de janeiro de 1966, e com o período letivo a iniciar-se, tudo quando podia ser, imediatamente, feito para dar início à arrancada contra a inércia no setor educacional, era recuperar a rêde escolar existente, estadual e municipal, e criar os turnos intermediários. Ao mesmo tempo que, por estas medidas, era ponderavelmente ampliado o número de matrículas, iniciava a Secretaria de Educação a construção de 136 salas de aula para o Ensino Primário e 130 salas [...] para o Ensino Médio [...].

Tendo recebido uma herança desalentadora no campo educacional, o Governo, a despeito dos recursos precários face à amplitude do problema pôde, ainda em 1966, abrir perspectivas novas à educação quer pelas realizações materiais quer pela fixação de uma nova e dinâmica política educacional. (MARANHÃO, 1967)

A comparação dos índices educacionais entre os anos de 1966 a 1970 da gestão Sarney revelam uma transformação numérica instigante que suscita perguntas e análises sobre a política educacional adotada por um governo cujos resultados, entre eles, os do campo educacional, encontravam-se na composição do chamado, à época, "Milagre Maranhense".

Tabela 1-Alunos matriculados no primário - início do ano 1965 - 1969

\begin{tabular}{l|l|l|l}
\hline \multicolumn{1}{c|}{ Ano } & \multicolumn{1}{|c|}{ Total } & \multicolumn{1}{|c}{ Estadual } & \multicolumn{1}{c}{ Municipal } \\
\hline 1965 & 139.356 & 46667 & 92689 \\
\hline 1966 & 201266 & 66913 & 134353 \\
\hline 1967 & 248885 & 74236 & 174649 \\
\hline 1968 & 271603 & 74730 & 196873 \\
\hline 1969 & 307000 & 89000 & 218000 \\
\hline
\end{tabular}

Fonte: SARNEY, José. Mensagem do Governador José Sarney à Assembléia Legislativa do Estado. Maranhão, 1970. 
DOI: 10.47694/issn.2674-7758.v3.i7.2021.102123

Tabela 2- Alunos matriculados no secundário - início do ano 1965 - 1969

\begin{tabular}{l|l|l|l}
\hline \multicolumn{1}{c|}{ Ano } & \multicolumn{1}{|c|}{ Total } & \multicolumn{1}{c|}{ Estadual } & \multicolumn{1}{c}{ Municipal } \\
\hline 1965 & 4381 & 4381 & - \\
\hline 1966 & 6139 & 3850 & 2289 \\
\hline 1967 & 7221 & 4438 & 2783 \\
\hline 1968 & 10167 & 7092 & 3075 \\
\hline 1969 & 13022 & 9173 & 3849 \\
\hline
\end{tabular}

Fonte: SARNEY, José. Mensagem do Governador José Sarney à Assembléia Legislativa do Estado. Maranhão, 1970.

Como mostram as tabelas, os índices educacionais ${ }^{3}$ no Maranhão Novo eram ascendentes e experimentavam, segundo discursos da época, um tempo de revolução, progresso, modernidade e desenvolvimento. No que se refere ao número de escolas, se por um lado o número de estabelecimentos do ensino primário das duas redes havia dobrado, no que se refere aos cursos ginasiais, o Estado havia acrescentado aos 3 existentes em 1965 mais 84 ginásios até 1970. Dos técnicos da United States Agency for International Development (USAID), ouvia-se que a obra educacional que acontecia no Maranhão era “[...] de vulto, sem similar no Brasil” (O IMPARCIAL, 1971, p. 6).

No último ano de mandato, em discurso à Assembleia Legislativa, José Sarney, como que dando um relatório do alcance de seus objetivos iniciais, afirmava que o Maranhão era o Estado do Nordeste que mais crescia, falava da construção de estradas para a "grande batalha do desenvolvimento" e que em quatro anos, sua gestão havia atingido “[...] a níveis expressivos nos setores educacionais e de saúde, capacitando recursos humanos para romperem as barreiras do atraso e da pobreza." (SARNEY, 1970, p.3).

Esses traços e discursos suscitam perguntas como: Que projetos educacionais foram constituídos no bojo do governo de José Sarney no Maranhão? Sob que condições históricas se deu o crescimento numérico apresentado nos níveis primário e médio da educação maranhense nesse período? Existem correspondências entre os discursos que

\footnotetext{
${ }^{3}$ Ao longo do texto será mostrada a relação entre Estado e municípios na constituição desses índices.
} 
DOI: 10.47694/issn.2674-7758.v3.i7.2021.102123

apregoavam um novo tempo para a educação maranhense e a efetividade do projeto educacional do governo autodenominado Maranhão Novo?

\section{Sem educação não há desenvolvimento ${ }^{4}$}

A partir do lema "Trabalho e Progresso", o Maranhão Novo empreendeu uma renovação dos aparelhos de Estado, instalando institutos de pesquisa e assessoria para o planejamento do desenvolvimento socioeconômico. Foi criada a Superintendência do Desenvolvimento do Maranhão (SUDEMA), semelhança estadual da Superintendência de Desenvolvimento do Nordeste (SUDENE), que, sob parâmetros da "racionalidade científica”, ficou responsável pelo planejamento de uma moderna infraestrutura para o Estado. Sobre a escolha dos técnicos que compuseram o órgão, assim como o propósito maior do plano elaborado por este, Sarney afirmava:

Êsse plano de governo, confiado à elaboração de técnicos maranhenses de elevado gabarito, visa a implantar a condição de infra-estrutura e realizar investimentos sociais que possibilitem no Maranhão a grande arrancada de desenvolvimento que resumiremos nos seguintes itens: Reforma Administrativa, visando a moralização e a eficiência da máquina do governo; Energia e Transportes, Educação e Saúde, Fomento Agropecuário e Industrialização. (SARNEY, 1970, p.16 - grifos nossos).

Do I Programa de Governo da gestão Maranhão Novo, destacavam-se quatro sobre Educação e Cultura, entre as doze diretrizes gerais do plano, incluídas no item "Da adequação dos recursos humanos":

1.b - Capacitar a mão-de-obra para melhor utilização dos instrumentos de produção.

3.a - Incentivar a implantação de Indústrias e Serviços que dêem prevalência à utilização da mão-de-obra.

4.b - Incorporar populações à vida econômica e social do Estado.

4.d - Atuar no sentido de obter melhor qualificação da mão-de-obra. (MARANHÃO, 1968)

A prevalência implícita da ideologia desenvolvimentista no referido documento reforçava o discurso nacional de adaptação das massas e da formação dos recursos humanos para o progresso e o aumento da produtividade. Na gestão de José Sarney, todos

\footnotetext{
4 Trata-se de um excerto com um sentido amplamente repetido desde o governo de Newton Bello no Maranhão (1961-1966) e, de forma exponencial, pelos interlocutores do Governo Maranhão Novo.
}

Revista Escritas do Tempo - v. 3, n. 7, jan-abr/2021 - p. -123 
os níveis da educação seriam contemplados, resultando em expansão tanto no nível primário, quanto nos níveis médio e no superior. ${ }^{5}$

Em discursos proferidos fora do Estado, José Sarney, alegando as disparidades sociais e econômicas entre as regiões norte-nordeste e centro-sul e a necessidade de uma integração nacional, falava sobre uma frente ampla de todos que pudessem integrar o projeto de desenvolvimento desencadeado no Nordeste, com destaque para o Maranhão. $\mathrm{Na}$ condição de paraninfo de uma turma da Universidade Presbiteriana Mackenzie, em São Paulo, o governador maranhense convocava os recém-formados a desbravarem novas fronteiras, alegando que "O Grande Norte", a despeito de uma paisagem desoladora de subdesenvolvimento até então, havia despertado para o desenvolvimento, “[...] e eu estou aqui para despertar o vosso entusiasmo jovem para uma fronteira magnífica e desafiadora [...]. (SARNEY, 1970, p. 102).

Para o empresariado do centro-sul, Sarney deslocava as fronteiras do Maranhão, "porto das bandeiras" no passado, entrada da conquista amazônica, apresentando evidências históricas de que o Estado maranhense, além de suas características mediterrâneas, (SARNEY, 1970, p.83), "porto mais próximo dos grandes mercados da Europa, do Caribe e dos E.U.A" (Id. p.62), era o caminho natural de ocupação da Amazônia para o desenvolvimento:

Mas o fascínio sedutor da Amazônia continuou a atrair audaciosos pioneiros, enquanto a argúcia do colonizador português o impelia ao desbravamento das regiões virgens para lá plantar os marcos de sua presença e as guarnições de sua força que desestimulassem a cobiça de outros colonizadores. Seguindo os caminhos dessa audácia e desse instinto de garantia de posse, Francisco Caldeira Castelo Branco, partindo do Maranhão, atingiu a foz do Grande Rio e ali plantou a cidade de Belém. Mais tarde, o cabo Bento Maciel Parente, partindo do Maranhão atingia região do Rio Negro onde hoje se situa Manaus.

De São Luís saíram, portanto, as bandeiras de desbravamento e conquista da desconhecida selva Amazônica (SARNEY, 1970, p. 84).

O Estado que tenho a honra de governar está fazendo um sério esforço de planejamento e investimento precondicionantes de desenvolvimento [...] criaramse incentivos e estímulos fiscais para os investimentos e o Estado se dispõe, inclusive, a participar dos empreendimentos industriais de médio porte. (Id. p.89).

De imediato e a médio prazo será sem dúvida o Maranhão a unidade integrante da região Amazônica que soma as melhores oportunidades e oferece as maiores perspectivas para o investimento privado. (Id. p. 89).

\footnotetext{
${ }^{5}$ Neste trabalho, a análise recairá apenas sobre os dois primeiros níveis.
} 
DOI: 10.47694/issn.2674-7758.v3.i7.2021.102123

Gonçalves (2000) apresenta o caminho percorrido pelos pensadores do Maranhão Novo na transformação das fronteiras maranhenses situadas mais à Amazônia (inclusão de terras úmidas, fronteira agrícola) e menos ao Nordeste (região problema, zona semiárida) a partir de um discurso regionalista, com o fim de atrair investidores do centrosul, desbravadores dessas novas fronteiras. A eles foi dada a promessa pelo próprio governador: "No Maranhão, hoje, tais são as oportunidades que se abrem em leque, no seu contexto geoeconômico, que - para usar uma expressão bem nordestina - 'quem chegar primeiro tem água fresca e rêde no alpendre"”. (Id. p.78). Além da sedução da paisagem maranhense, que deveria continuar atraindo desbravadores, José Sarney acrescentava outras, garantindo aos investidores: “[...] segurança em termos futuros de suas empresas e de seus balanços [...], [...] política de estímulos fiscais", enfim, condições que assegurassem “[...] rendimentos certos”. (Id., p.67, 76, 78).

Ao mesmo tempo em que os chamados "homens de empresa" são privilegiados nos enunciados do Maranhão Novo, os pequenos agricultores e sua produção são excluídos desses discursos e programas oficiais. Em outras palavras: "As unidades produtivas de base familiar foram preteridas pelos projetos agropecuários de grande dimensão" (GONÇALVES, 2000, p.186). Na fabricação desse novo Maranhão, os grupos empreendedores receberiam muitos incentivos, entre eles, a chamada Lei de Terras $\mathrm{n}^{\mathbf{o}}$ 2.979/69, responsável pela reestruturação do mercado de terras no Maranhão, a partir de então, espaço legitimado para as atividades agroindustriais e pecuárias de grande porte, resultando na compressão do agricultor familiar a um espaço cada vez mais reduzido e no aprofundamento das tensões e dos conflitos no campo. Esse contexto oferece traços relevantes para a análise do projeto educacional do Maranhão Novo de José Sarney.

A partir desses traços, percebe-se que a categoria desenvolvimento é acionada pelo governo de José Sarney de forma recorrente, configurando discursos e planos governamentais. No presente texto, opera-se com a noção de desenvolvimento tomado como um conjunto de estratégias nacionais, elaboradas com o fim de promover mudanças rumo a um ideal de nação próspera economicamente. O discurso desenvolvimentista foi acionado, principalmente, a partir da segunda metade da década de 1950, com o fim de apregoar a nivelação dos países da América Latina aos chamados “países centrais".

Nesse período, o desenvolvimento foi continuamente associado à ideia de modernidade e ao setor de mercado e de expansão do capital, enquanto que o seu oposto, o subdesenvolvimento, foi correlacionado ao setor não formal e de subsistência. Dessa 
DOI: 10.47694/issn.2674-7758.v3.i7.2021.102123

forma, o binômio desenvolvimento-progresso foi constituído em contraposição ao arcaico-atrasado.

Em meio à composição dessa rede discursiva, a educação foi paulatinamente evidenciada como importante campo de investimento para a integração das sociedades "periféricas" no âmbito do capitalismo internacional. Tal vinculação estava embasada pela Teoria do Capital Humano de Theodore W. Schultz, que apresentava o trabalho humano qualificado pela educação como fator essencial para a ampliação da produtividade e, consequentemente, aumento das taxas de lucro do capital. Essa teoria resultaria na concepção tecnicista que subsidiaria o campo educacional brasileiro, prevalecendo por muito tempo nesse cenário, influenciando-o.

O diálogo com essa categoria se deu na análise dos três projetos elaborados pela gestão Maranhão Novo para os níveis primário e secundário, a saber, o Projeto João de Barro (1967), a Televisão Educativa (1968) e o Projeto Bandeirante (1968). Procura-se destacar a rede discursiva que gravitava em torno desses projetos, além de evidenciar correspondências entre suas propostas e efetividade destas. A análise documental se deu a partir dos textos desses projetos, mensagens governamentais e matérias jornalísticas.

\section{As escolas João de Barro e o desenvolvimento: uma proposta educacional para o camponês maranhense}

As escolas "João de Barro" foram idealizadas com o objetivo de sanar o que o Maranhão Novo considerava como ponto maior de estrangulamento educacional do Estado: o ensino primário, principalmente, o da zona rural. $\mathrm{O}$ objetivo era a alfabetização das populações rurais em articulação com seu cotidiano, conscientizando-as das condições de "[...] subdesenvolvimento e de suas reais possibilidades de, através de um esforço comum inteligente, mudar esse estado de cousas." (PROJETO JOÃO DE BARRO, 1967, p. 5).

No projeto, o camponês era definido como aquele que, “[...] marginalizado dos recursos culturais e econômicos existentes", encontrava-se "[...] incapaz de, por si, inserir-se no processo de desenvolvimento global do Estado". Assim, era necessário um trabalho que mobilizasse a massa camponesa "[...] para uma participação mais ativa no processo de desenvolvimento de Estado e fornecendo-lhes o mínimo do instrumental necessário. (PROJETO JOÃO DE BARRO, 1967, p. 2,4 - grifo nosso). 
DOI: 10.47694/issn.2674-7758.v3.i7.2021.102123

Ao definir o camponês maranhense como incapaz e carente de conscientização, o projeto negava a historicidade da mobilização de camponeses no Maranhão. Em 1956, por exemplo, várias associações de lavradores espalhadas pelo Estado, em articulação, criaram a Associação dos Trabalhadores Agrícolas do Maranhão (ATAM), constituída no espírito de uma luta mais expressiva e organizada do campesinato maranhense em torno da reforma agrária.

Conforme Kreuz (1983), dos cinco integrantes que em 1967 elaboraram o projeto, quatro pertenciam ao Movimento de Educação de Base (MEB), que havia sido desarticulado no Maranhão pela repressão militar. Nacionalmente, após o golpe de 1964, o MEB ainda permaneceu como único movimento de educação e cultura popular até 1965. A existência até aquele ano se deu por força do convênio com a União, que havia fixado datas-bases de 1961 a 1965. Já em 1966, a hierarquia da Igreja Católica havia recuado dos princípios que guiavam o MEB até então, vindo o movimento a perder suas características de educação popular, tornando-se uma forma tardia de educação primária (CUNHA, 1985). Essas informações sinalizam, quase que imediatamente, para uma problematização do Projeto João de Barro no contexto maranhense, suas intenções e sua efetividade.

O objetivo geral do Projeto João de Barro apontava para a integração do camponês no apregoado desenvolvimento do Maranhão Novo: "Através de um processo de educação integral, em nível elementar, inserir o homem rural no processo de desenvolvimento socioeconômico racionalizado" (PROJETO JOÃO DE BARRO, 1967, p.1). Por sua vez, no II Encontro de Investidores em Salvador, Sarney assegurava ao empresariado presente que o Maranhão ampliava seus "[...] programas de formação acelerada de mão-de-obra". (SARNEY, 1970, p.62).

O ponto de partida para a implantação do Projeto João de Barro nas comunidades rurais era a construção, pelo próprio camponês, de uma escola de baixo custo: chão batido, taipa e cobertura de palha. Elas funcionariam como centros animadores e teria, na figura do "monitor de escola", a liderança que movimentaria a comunidade em busca de "[...] um maior bem estar imediato". (PROJETO JOÃO DE BARRO, 1967, p. 2).

Segundo o documento, os monitores das Escolas João de Barro, escolhidos entre os próprios camponeses, deveriam ser uma das lideranças locais, o que certamente era uma forma de conter a "fermentação nos campos", expressão utilizada por José Sarney em discurso a investidores:

Revista Escritas do Tempo - v. 3, n. 7, jan-abr/2021 - p. -123 
DOI: 10.47694/issn.2674-7758.v3.i7.2021.102123

A SUDENE foi criada como um organismo destinado a formular uma política específica para o Nordeste, onde uma economia integrada num processo de decadência e deterioração constante assegurava níveis baixíssimos de renda, com graves perigos à ordem social que se refletiam, por um fenômeno de simpatia, a toda estrutura política nacional, abalada pela fermentação nos campos [...]. (SARNEY, 1970, p.63 - grifos nossos).

A integração da escola com a comunidade era essencial para o sucesso do projeto. O ponto de partida dessa integração era a construção do próprio espaço escolar, que, a partir da lógica camponesa do mutirão e ajuda mútua, deveria ser feito a partir do padrão das moradias do povoado: de taipa, chão batido e coberto de palha. Daí o nome "João de Barro", uma alusão ao pássaro que constrói seu próprio ninho de barro. Neste sentido, segundo a redação do projeto, era preciso

[...] um trabalho de valorização das Comunidades que não permita à população alimentar uma atitude de passivismo: ficar esperando tudo dos poderes mais altos ou da descrença: afirmar que nada se pode fazer para mudar a situação [...]. (PROJETO JOÃO DE BARRO, 1967, p. 4).

Os noticiários da época destacaram o início do projeto e o seu objetivo:

O Projeto João de Barro teve início em setembro do ano de 1967 como esquêma educacional implantado no Maranhão pelo Prof. Cabral Marques, sob o Governo José Sarney, para atender às populações rurais, onde maior índice de analfabetismo se registra. (PAES, 1968, p. 1).

No primeiro semestre de 1968, a matrícula nessas escolas chegou ao número de 2.799 alunos, sendo 657 adultos e 2.142 crianças e adolescentes (menores de 14 anos). A rapidez entre a elaboração do projeto e início de sua execução só pode ser justificada mediante a existência de toda uma base do MEB aproveitada pela equipe de trabalho.

Inicialmente, em convênios com as prefeituras locais, foram construídas mais de 1.000 escolas, sendo essas construções realizadas em parceria com as comunidades locais. Sobre elas, era noticiado:

São as chamadas escolas João de Barro, feitas de taipa e barro cru, cobertas de palha de babaçu, que chegaram a revolucionar o ensino, representando uma das grandes decisões do Sr. José Sarney para alfabetizar a gente do seu Estado (PAES, 1968, p.1 - grifo nosso). 
DOI: 10.47694/issn.2674-7758.v3.i7.2021.102123

Tal "revolução" era realizada com um mínimo de recursos pelo Estado. A Secretaria Estadual de Educação oferecia treinamento técnico aos líderes locais e o governo estadual era responsável por pagar pequenos salários aos monitores do projeto. Segundo Ribeiro (1985), o Estado subvencionava tecnicamente o projeto, além de colocar à sua disposição um pequeno aporte de recursos financeiros, somando-se a esses uma grande participação das comunidades contempladas. Essa economia de recursos era elogiada pela imprensa oficial da seguinte forma:

Embora o projeto conte atualmente com duas mil e onze (2.011) escolas desse tipo, instaladas em setenta e oito comunidades e com o impressionante número de cento e oitenta mil novecentos e noventa alunos matriculados, somente vinte e uma pessoas trabalham na execução do projeto, inclusive a coordenadora. ( $\mathrm{O}$ IMPARCIAL, 1971, p.10).

De caráter conservador, determinada e controlada pelo centro do poder, era uma "revolução" cuja lógica entre custo e benefício exaltava constantemente o alcance quantitativo: "Em números globais, sobem a mais de 800 as escolas 'João de Barro', desde a instalação do projeto em 1967, preenchendo uma lacuna no campo educacional e possibilitando a instrução inicial a grande parte da população interiorana." (O IMPARCIAL, 1971, p. 10).

Adiante, na mesma matéria jornalística, lê-se que o pedido de aldeias indígenas pelas escolas “João de Barro" estava sendo estudado pela Secretaria de Educação. Em outro momento, apresenta-se o resultado prático dessas escolas na vida das comunidades rurais atendidas:

Assim, é que pessoas que há pouco tempo assinavam seus recibos e documentos com impressão digital, por não saberem ler, hoje já sabem assinar seu nome, escrever e contar o necessário para satisfazer aos seus negócios e transações no seio da comunidade. Além disso, muitos têm prosperado um pouquinho, devido aos ensinamentos recebidos, deixando de residir em míseras palhoças de chão batido para morar em casinhas que receberam seus melhoramentos, graças a melhores ganhos de seus possuidores. (O IMPARCIAL, 1971, p.10 - grifo nosso).

A narração, quase idílica, não se dá conta de que, ao afirmar que eram miseráveis as palhoças de chão batido onde morava o camponês maranhense, era miserável, também, a escola de palha e chão batido oferecida a este.

Revista Escritas do Tempo - v. 3, n. 7, jan-abr/2021 - p. -123 
DOI: 10.47694/issn.2674-7758.v3.i7.2021.102123

Se por um lado o estado procurou satisfazer o anseio educacional das populações rurais através do projeto, por outro, garantiu terra e capital aos empresários, investidores oriundos do centro-sul, ao lado de mão de obra com o mínimo de capacitação educacional. A presença dessas escolas estava no bojo de um projeto que delineava um novo homem para um novo Maranhão, com novas tecnologias que modernizassem as atividades agropecuárias. Paralelo à instrução elementar, estava sendo garantida a transformação do camponês em um trabalhador rural ou operário da construção civil das grandes empresas que que se instalavam no Estado.

Para Ribeiro (1985), paulatinamente, o camponês maranhense foi deixando a escola "João de Barro" por ela não cumprir a promessa de solução dos seus problemas, como divulgavam os técnicos da Secretaria de Educação nas reuniões periódicas, e ainda por constatar que sua participação foi, aos poucos, reduzida à construção do barracão que deveria seguir um modelo pré-fixado. O autoritarismo, próprio da época, foi limitando a participação camponesa não apenas em sua própria escola, mas também em sindicatos, pastorais e associações que pudessem possibilitar a essas populações espaço para crítica ou reivindicação. A autora ainda ressalta que o fermento da mobilização do início da década de 1960, presente no meio rural maranhense, havia sido contido com a ajuda das escolas "João de Barro", cuja base discursiva constituía-se exatamente no oposto: fortalecimento e autonomia do trabalhador rural.

\section{TVE/Maranhão: tecnologia à serviço da educação e do desenvolvimento}

No que se refere ao ensino secundário do Estado, a gestão Sarney encontrou uma rede de 86 cursos. Desses, 80 pertenciam à iniciativa particular e apenas seis eram públicos: dois federais, três estaduais e um municipal. Segundo Kreuz (1983), no início daquela década, somente $4,6 \%$ da população maranhense que poderia frequentar o ensino médio estava cursando esse nível.

Ainda no segundo ano do mandato de José Sarney, a realidade numérica do secundário apresentava poucas mudanças: os cursos estaduais haviam aumentado de 2 para 3 unidades e a rede particular havia aumentado em cerca de $20 \%$ o seu atendimento, matriculando 22.155 alunos no início de 1967, enquanto que, na rede pública, as matrículas iniciais chegavam ao número de apenas 8.818 alunos (BRASIL, 1970, v. 31). Dos 128 municípios, à época, apenas 28 possuíam cursos de ensino médio, sendo que 
dois estaduais se encontravam localizados em São Luís: um ginasial e outro normal, ambos funcionando no Liceu Maranhense.

Ainda no segundo ano da gestão Maranhão Novo, a população maranhense estimada entre 11 e 21 anos era de 840.000, e as matrículas no secundário atendiam a apenas 3,68\% dessa população no nível médio (MARANHÃO, 1971, v. 1). É nesse cenário que foi constituído um outro projeto educacional pela gestão Maranhão Novo: a Televisão Escola do Maranhão (TVE/MA).

Segundo Helena Bomeny (1981), a ideia da televisão como substituta do professor, não era nova no Maranhão e nem pertencia à equipe de José Sarney. Renato Archer, seu opositor nas campanhas eleitorais de 1965, já a defendia como alternativa viável diante da escassez de recursos no Estado e da falta de professores. Em entrevista concedida à Bomeny, Archer teria afirmado: "O Maranhão nunca teria dinheiro para construir todas as escolas de que precisava. E se tivesse, nunca teria condições, tempo nem disponibilidade para formar os professores" (BOMENY, 1981, p. 28).

Nesse sentido, o Maranhão Novo utilizou de argumentos como a falta de professores qualificados e a urgência da oferta de vagas às camadas populares do meio urbano para a implantação da TVE em 1969. Bonfim (1985) destaca que, apesar dos esforços de convencimento, nacionalmente o MEC não acreditou que o Maranhão tivesse condições para fazer funcionar tal projeto, o que resultou na falta de apoio federal.

A Lei que criou a Fundação Maranhense de Televisão Educativa assegurava que sua instituição se dava “[...] segundo os modernos princípios da pedagogia” e destacava como seu público alvo a juventude, de modo a integrá-la “[...] no processo de desenvolvimento do Estado". Destacava, ainda, sobre a necessidade de preparo dos professores, que no projeto atuariam para o "[...] emprego dos métodos adaptados aos modernos recursos técnicos". Além disso, a TVE/MA não se restringiria apenas ao ensino médio e, "[...] através de cursos regulares ou de madureza", ofereceria ainda "[...] ensino primário complementar em apoio ao sistema educacional do Estado", cursos e atividades para adultos, “[...] visando a alfabetização funcional e a preparação e melhoria da mãode-obra" (MARANHÃO, 1970).

Ainda segundo Bonfim (1985), à despeito de críticas locais por parte do corpo docente da época, que sentia seu emprego ameaçado, e do não apoio federal, em julho de

\footnotetext{
${ }^{6}$ De acordo com o artigo 99 da LDB 4024/61, tratava-se de um exame que dava direito à certificação do curso ginasial após estudos realizados sem observância do regime escolar (BRASIL, 1961).
} 
DOI: 10.47694/issn.2674-7758.v3.i7.2021.102123

1968, os estudos para implantação da TVE/MA foram organizados. Em janeiro de 1969, ela já estava funcionando no Estado, a partir do Projeto de Lei no 58/69 que, segundo a autora, objetivava o preparo de mão de obra no meio urbano pela massificação do ensino secundário. A pesquisadora assinala que aparelhos técnicos pouco sofisticados foram adquiridos e que a TVE passou a funcionar na sede da Secretaria de Educação, sendo incorporada a esta como um projeto seu.

Sob a coordenação do padre José Manuel de Macedo Costa, pequenas equipes de professores passaram a elaborar todo o programa curricular a ser transmitido pela TVE. O acompanhamento e direcionamento das tarefas em sala de aula ficariam sob a responsabilidade do professor polivalente chamado "orientador da aprendizagem", que receberia, à época, um salário pouco maior que o do professor normalista. (KREUZ, 1983).

Em 1969, 1.304 alunos foram matriculados na primeira série ginasial oferecida pela TVE/MA e, em 1970, o número de telessalas já era de 161, distribuídas em dois municípios, atendendo a 6.251 alunos, um grande acréscimo numérico em um curto período de tempo. A pesquisa de Bomeny (1981) revela que, se por um lado, a proposta estava pautada na ideologia desenvolvimentista, por outro, encontrava-se comprometida nacionalmente com o autoritarismo e a centralização que se estabelecera no Brasil a partir de 1964.

Previsto no I Programa de Governo do Estado do Maranhão e utilizando a estrutura física e metodológica da TVE, o Curso de Preparação ao Exame Madureza Ginasial foi também implantado em 1970, objetivando atingir adultos e adolescentes trabalhadores do meio urbano. Segundo Bonfim (1985), naquele mesmo ano, funcionaram nesse projeto 102 telessalas do Projeto Madureza, atingindo matrículas de 4.200 alunos. A autora destaca ainda que, “[...] desde a fase inicial de seu funcionamento, o Curso teria grande repercussão: agora era a vez do trabalhador ser encampado pela sistemática que já atingira parte da população de São Luís, através dos cursos noturnos” (BONFIM, 1985, p.178).

Na década de 1980, a TVE/Maranhão atingia 25 municípios atendendo 20.620 telealunos das quatro últimas séries do então primeiro grau, distribuídos em 522 telessalas. Tal experiência permaneceria no cenário maranhense até o ano de 2006.

Diante da impossibilidade da TVE atingir o vasto território maranhense, foi elaborado o Projeto Bandeirante, com o objetivo de levar às zonas de necessidade e 
clientela comprovadas, o ensino médio ginasial, cujas bases profissionalizantes deveriam estar a serviço de um novo Maranhão. A intensificação de pressões municipais em torno de uma educação pública nesse nível, aliado a incentivos nacionais e a decisões do poder estadual, são fatores que estão no bojo de um projeto cuja pretensão era desbravar as inteligências do interior do Maranhão para o desenvolvimento.

Em 1968, os Ginásios Bandeirantes, sob o discurso da inovação e da modernidade, foram instalados em 35 municípios do interior e, ao longo de quatro anos, em mais 49, redefinindo a face do ensino secundário público maranhense. Os discursos em torno desse projeto, suas pretensões, sua distribuição político-geográfica e a concretização prática de seus objetivos, são aspectos, dentre outros, destacados a partir de agora.

\section{Projeto Bandeirante: desbravando inteligências para o desenvolvimento}

Enquanto que o nome da escola do camponês maranhense estabelecia a relação entre significante "João de Barro" - em alusão ao pássaro que constrói seu próprio ninho - e significado - camponês que constrói sua própria escola -, a designação simbólica utilizada para um dos projetos do ensino médio, "Bandeirante”, não se restringia apenas ao campo educacional. Se por um lado a gestão Sarney pretendia ser desbravadora das "inteligências dos maranhenses", na condição de "Bandeirante", por outro, era essencial atrair outros "desbravadores" das riquezas naturais do Estado, suscitando questionamentos acerca de como o primeiro projeto é colocado a serviço do segundo.

O Projeto Bandeirante era "[...] uma das soluções para um aspecto do problema do ensino em nível médio" e deveria ser ponte entre o primário e o ensino superior, além de promover "[...] formação de mão de obra especializada para o desenvolvimento, o que só poderá ocorrer, no sistema educacional, a partir do nível médio”. (MARANHÃO, 1968, p.1). Nesse sentido, encontrava-se em consonância com o discurso do governador que enfatizava uma educação que tivesse por objetivo “[...] qualificar os alunos, em qualquer dos estágios de sua formação, para o trabalho" (MARANHÃO, 1967). Também o art. $1^{\circ}$ do Regimento Interno dos Ginásios destacava:

Os Ginásios Bandeirantes [...] têm por objetivo principal ministrar o ensino secundário profissional dentro da legislação vigente, proporcionando aos alunos educação integral e formação profissional, variando de acordo com as necessidades locais. (MARANHÃO, 1968, p. 3).

Revista Escritas do Tempo - v. 3, n. 7, jan-abr/2021 - p. -123 
DOI: 10.47694/issn.2674-7758.v3.i7.2021.102123

O discurso de desenvolvimento do Estado a partir do secundário forjava para o projeto um universo simbólico reforçado em vários espaços. Assim, a chegada de um Bandeirante na cidade de Lima Campos era adjetivada em noticiários da época da seguinte forma: "Funcionando na cidade de Lima Campos, o Ginásio Bandeirante, que veio preencher uma fraude lacuna no setor educacional e trazer um marco de progresso para esta região [...]" (JORNAL DO DIA, 1972, p. 3 - grifo nosso). Nos documentos de solicitação dos gestores municipais, constatamos que tal discurso alcançara também as justificativas destes na defesa da instalação de um Bandeirante em suas cidades:

A principal modalidade ou o melhor meio capital para financiarmos a destruição do subdesenvolvimento, é investindo recursos na educação de um povo. (PERI MIRIM, 1967 - grifo nosso).

[...] possui o Município de Humberto de Campos um índice educacional primário que, anualmente prepara quase uma centena de jovens que, à falta de um estabelecimento de nível secundário, ficam marginalizados do ensino, imprescindível ao aprimoramento de suas faculdades intelectuais e preparação para os misteres da vida adulta. Disso resulta um baixo nível intelectual da população que, desse modo, jamais poderá se integrar no processo desenvolvimentista, posto que, estagnada e sem condições de adquirir uma mentalidade voltada para a realidade e progresso do meio. [...]. Daí, ser justo, patriótico e fundamental, não só reivindicar, mas também lutar, quebrar barreiras, aparentemente intransponíveis, pela fundação de um Ginásio naquele Município, pois sem educação não há que falar em desenvolvimento e progresso. (HUMBERTO DE CAMPOS, 1967 - grifo nosso).

Sabemos, então que o desenvolvimento de um País ou de uma Região não poderá alcançar maior surto de progresso, sem que se dê condições ou meios para a educação de suas populações. (MAGALHÃES DE ALMEIDA, 1970 - grifo nosso).

Nas informações sobre a inauguração do Ginásio Bandeirante de Primeira Cruz, encontramos vestígios de como o discurso desenvolvimentista foi expresso aos alunos, logo no primeiro dia de aula:

Com imensa vibração, foi inaugurado, no dia $1^{\circ}$ último, em Primeira Cruz o Ginásio Bandeirante daquela cidade, sendo, na oportunidade, proferida pelo Dr. José Ribamar Goulart Heluy, Juiz de Direito da Comarca de Humberto de Campos e Diretor do Ginásio dessa cidade, a aula inaugural que abordou "o trabalho e as transformações sócio-econômicas.” (JORNAL DO DIA, 1968, p. $5)$.

Expressões e sínteses de um discurso nacional que eram resultados de uma longa construção histórica, os objetivos do Projeto Bandeirante defendiam uma educação 
DOI: 10.47694/issn.2674-7758.v3.i7.2021.102123

integral que possibilitasse a inserção do educando em seu meio, apresentando ainda a possibilidade de profissionalização imediata deste:

1- Levar à zona de necessidade e clientela comprovada a educação integral, através do Ensino Médio;

2- Induzir a comunidade a uma participação efetiva no processo de desenvolvimento sócio-econômico e em particular na solução do problema educacional.

3- Criar hábitos, atitudes e convicções no educando que o preparem para uma vida responsável por si e pela comunidade em que vive.

4- Dar ao educando condições de consumir bens técnicos, institucionais e culturais.

5- Despertar o interesse pela educação técnica, agrícola, artística, prática e científica.

6- Promover a fixação do homem ao seu meio proporcionando-lhe formação profissional de nível médio.

7- Suprir a falta de professores primários. (MARANHÃO, 1968, p. 2).

Educação integral, participação efetiva da comunidade no desenvolvimento socioeconômico, fixação do homem em sua comunidade, formação profissional! A proposta de ensino médio do Maranhão Novo assumia um caráter inovador, destacado assim pela imprensa da época:

Serão ginásios modernos, funcionais ao desenvolvimento da nossa região, o que virá preparar em tempo recorde o nosso povo, as nossas novas gerações para a era do progresso já implantada no Maranhão. (O IMPARCIAL, 1968, p. 8).

Em 1968, foram instalados 35 ginásios, que acrescentariam o nome da cidade contemplada logo a frente da designação “Ginásio Bandeirante”. Em alguns locais, essa composição apresentou pequenas variações, como na cidade de Caxias, em que o ginásio foi chamado "Ginásio Bandeirante Duque de Caxias".

Sobre o número de turmas e turnos de funcionamentos, o projeto esclarecia que as necessidades e condições locais determinariam esses aspectos e as turmas iniciais seriam variáveis “[...] em cada Ginásio, conforme a necessidade e participação financeira dos municípios e da comunidade." (MARANHÃO, 1968, p.1 - grifo nosso). Sobre as instalações físicas para os Ginásios Bandeirantes, as orientações eram que “[...] inicialmente os prédios escolares existentes nas sedes dos municípios, quer sejam do estado ou da prefeitura" deveriam ser aproveitados (MARANHÃO, 1968, p. 1). Mais adiante, no mesmo documento, é informado que na visita do inspetor a esses prédios 
DOI: 10.47694/issn.2674-7758.v3.i7.2021.102123

deveria ser observada a existência de condições mínimas indispensáveis para o funcionamento dos ginásios.

A racionalização de recursos era, sem dúvida, uma das principais marcas da gestão educacional desse período. Se ao camponês foi oferecida uma casa de palha e chão batido como escola, e às massas da capital aulas a partir de aparelhos de TV pouco sofisticados em grandes galpões de prédios públicos (Bonfim, 1985), a partir do Projeto Bandeirante foi disponibilizado ao maranhense um ginásio de baixo custo, geralmente aproveitandose instalações já existentes nos municípios, dividindo-se despesas com estes.

A pesquisa de Nascimento (2013) evidenciou que a racionalização econômica no aproveitamento de prédios já existentes, em grande parte, antigas residências familiares transformadas em escolas, encontra-se implícita em modestas descrições, como o relatório que apresentava o espaço onde funcionaria o Ginásio Bandeirante de Peri Mirim:

O prédio no qual irá funcionar o ginásio, pertence ao Estado e está conservado. Possui 6 salas de aula, um pequeno reservado onde irá funcionar a secretaria, dois sanitários (bons), uma pequena área coberta a qual será destinada para a recreação dos alunos, já foi instalada uma caixa d'água. (MENDONÇA, 1968).

No início de 1969, era noticiado que mais ginásios seriam implantados, como parte de uma expansão planejada. Com a criação de mais 22 novos ginásios, encontravamse, a partir daquele ano, 58,76\% dos municípios maranhenses contemplados com o ensino secundário ginasial público. Em 1970, finalmente, o secundário público maranhense ultrapassou, em número de cursos, o ensino particular. Com a implantação de mais 27 ginásios, passou a rede pública estadual a contar com um total de 84 Ginásios Bandeirantes, além dos cursos já existentes, enquanto a rede particular contava com 66 unidades (BRASIL, 1971, v. 32). No entanto, se o número de cursos públicos já ultrapassava os da rede privada no $1^{\circ}$ ciclo do ensino médio, no que se referia às matrículas, a realidade era outra quando comparadas as duas redes:

Tabela 3- Matrículas do ensino médio no Maranhão Redes Pública e Particular - $1^{\circ}$ ciclo $-1968-1970$

\begin{tabular}{l|l|l|l}
\hline \multicolumn{1}{c|}{ Ano } & \multicolumn{1}{|c|}{ Total } & \multicolumn{1}{|c}{ Público } & \multicolumn{1}{c}{ Particular } \\
\hline 1968 & 35.216 & 7.092 & 28.134 \\
\hline 1969 & 38.017 & 11.786 & 26.231 \\
\hline
\end{tabular}


DOI: 10.47694/issn.2674-7758.v3.i7.2021.102123

\begin{tabular}{l|l|l|l}
\hline 1970 & 40.439 & 13.742 & 26.697 \\
\hline
\end{tabular}

Fonte: BRASIL. Anuário Estatístico do Brasil, 1971. Rio de Janeiro: IBGE, v. 29,32, 1969, 1971.

Como se percebe, a instalação de 84 ginásios em três anos não significava, proporcionalmente, o aumento de matrículas no ensino secundário público e de responsabilidade do Estado. Apesar de ultrapassar quantitativamente a rede particular em termos de unidades escolares, a segunda rede continuaria dominando a oferta de vagas no $1^{\circ}$ ciclo do ensino médio.

O reduzido número de turmas implantadas inicialmente em cada ginásio pode ser explicado, entre outros fatores, pelo reduzido quadro docente para atuação no Estado, ainda que fosse só com a formação em nível de magistério. Segundo Barbosa (2011), dos 2.722 professores que atuavam no ensino médio maranhense, apenas 701 eram licenciados em Faculdades de Ciências e Letras, à época. Dos licenciados, somente 255 lecionavam em cidades do interior do estado.

A longo prazo, a solução para a falta de professores com habilitação para o ensino secundário foi a criação, a partir da Lei no 2821, de 23 de fevereiro de 1968, da Faculdade de Formação de Professores de Ensino Médio de Caxias (FFPEM). Ela foi instalada em 1970, oferecendo três cursos de licenciatura curta: Filosofia, Ciências e Letras, “[...] com cursos regulares e parcelados em período de férias, sob a coordenação pedagógica da Missão Docente da Faculdade de Filosofia, Letras e Ciências Humanas (FFLCH) da Universidade de São Paulo (USP)" (BARBOSA, 2011, p. 37). De forma imediata, a carência de professores formados teria um efeito direto, aliado a outros fatores, na expansão e qualidade da rede estadual de ginásios.

Em 1971, o ritmo de criação dos Ginásios Bandeirantes começou a decrescer, sendo instalados apenas 8 em 1973, só mais 2: um na cidade de Grajaú e outro em São Domingos do Maranhão. Apesar de percalços e contradições, a constituição dessa rede ginasial permanece como importante página da história da educação maranhense.

\section{Considerações finais}

O discurso desenvolvimentista foi extensamente acionado pela administração de José Sarney no Maranhão. Entre as aclamadas revoluções impulsionadas pelo Maranhão Novo, encontrava-se as do campo educacional. São expressivos os números de matrículas 
DOI: 10.47694/issn.2674-7758.v3.i7.2021.102123

tanto no primário quanto no secundário, bem como a expansão da rede ginasial estadual: 84 ginásios durante os anos da sua gestão.

Apesar de discursos destacarem a modernidade, o progresso e a existência de uma verdadeira transformação na educação maranhense, a análise de traços da efetividade dos projetos do Maranhão Novo, a saber, João de Barro, TVE/MA e Bandeirante revelam que a racionalização de recursos por parte do Estado constituía a principal contradição a esses discursos.

Do Projeto João de Barro, efetivado com ínfimos investimentos estaduais, enfatizamos a miséria dos barracões de palha e chão batido construídos pelos próprios camponeses e que foram chamados de "escolas", a formação insuficiente de monitores para atuarem no lugar de professores e a imagem distorcida do camponês como aquele que precisava ser conduzido pelo Estado. Da TVE/MA, ressaltamos a rapidez entre elaboração e efetivação de um projeto que se pretendia embasado nos "modernos princípios da Pedagogia", a racionalização de recursos, o espaço de formação para submissão à ordem política da época.

Constatamos que a rápida expansão do número de Ginásios Bandeirantes, não significou, necessariamente, a popularização do ensino secundário no Maranhão. A rede particular de ensino, mesmo apresentando um número de cursos inferior aos da rede pública, continuava dominando o índice de matrículas nesse nível. O aproveitamento do que existia nos municípios foi a principal marca dos espaços físicos e mobiliários oferecidos a esses ginásios, revelando mais uma vez uma "revolução" educacional com base na racionalização de recursos que, adicionada a outros aspectos como a falta de professores formados para o ensino médio, põe em xeque discursos forjados no sentido de estabelecer novos tempos para a educação maranhense.

Por fim, uma pergunta à guisa de conclusão e de provocação aos historiadores das políticas públicas educacionais: Que cenários pode revelar a análise comparativa entre discursos e a efetividade de planos e projetos forjados para o convencimento de um constante devir no campo educacional dos diversos estados brasileiros?

\section{Referências}

BARBOSA, Roldão Ribeiro. Da Faculdade De Formação De Professores Ao Centro De Estudos Superiores: uma história da instalação e consolidação do Ensino Superior em Caxias (1968 - 1994). Dissertação de Mestrado apresentada no Programa de PósGraduação em Educação. UFPI: Teresina, 2011. 
DOI: 10.47694/issn.2674-7758.v3.i7.2021.102123

BOMENY, Helena. Paraíso tropical: a ideologia do civismo na TVE do Maranhão. Rio de Janeiro: Achiamé, 1981.

BONFIM, Maria Núbia Barbosa. Do velho ao novo: política e educação no Maranhão. São Luís - MA: UFMA, 1985.

BRASIL. Anuário Estatístico do Brasil, 1970. Rio de Janeiro: IBGE, v. 31, 1970.

CUNHA, Luiz Antônio. O golpe na educação. Rio de Janeiro: Jorge Zahar, 1985.

Ginásio Bandeirante de Humberto de Campos. Histórico do Município de Humberto de Campos. 1967. Datilografado.

Ginásio Bandeirante de Magalhães de Almeida. Histórico da Região do Baixo Paranaíba e Perspectiva de Desenvolvimento do Município de Magalhães de Almeida - Justificativa da Criação do Ginásio Bandeirante. Raimundo Olinda dos Santos - Prefeito, 1970. Datilografado.

GINÁSIO BANDEIRANTE DE PERI MIRIM. Histórico do Município de Peri Mirim. 1967. Datilografado.

Relatório de Inspeção. José Geraldo de Menezes Mendonça - Inspetor. São Luís, 05 de janeiro de 1968. Datilografado.

GONÇALVES, Maria de Fátima da Costa. A reinvenção do Maranhão dinástico. São Luís: UFMA/PROIN/CS, 2000.

KREUZ, Arno. O projeto “João de Barro" e o poder político no Maranhão. São Luís: UFMA, 1983.

JORNAL DO DIA. Ginásio bandeirante em Lima Campos. São Luís, 06 fev. 1972.

. Primeira Cruz inaugurou primeiro Ginásio Bandeirante. São Luís, 8 mai. 1968.

MARANHÃO. Governador, 1966-1971 (José Sarney). Mensagem à Assembléia Legislativa. São Luís: SIOGE, 1967.

. I Programa de Governo do Estado do Maranhão. Administração José Sarney. SUDEMA. São Luís, 1968. Mimeografado.

Secretaria de Estado de Educação. Projeto João de Barro. Secretaria de Educação. [s. d.]. Mimeografado.

Mimeografado.

Secretaria de Estado de Educação. Projeto Bandeirante. São Luís, 1968.

Revista Escritas do Tempo - v. 3, n. 7, jan-abr/2021 - p. -123 
DOI: 10.47694/issn.2674-7758.v3.i7.2021.102123

Secretaria de Estado dos Negócios de Educação e Cultura. Regimento dos Ginásios Polivalentes do Projeto Bandeirante, São Luís: 1968. Cap. 3. p. 3. Mimeografado.

DECRETO No 4095 DE 23 DE FEVEREIRO DE 1970. Diário Oficial do Estado, São Luís, Ano LXII. N.39, 27 fev.1970.

Anuário Estatístico do Maranhão de 1969 - ano base de 1968. Plano de Governo 1971/74. vol. I, São Luís: SIOGE,1971.

PAES, Eyder. Sarney dinamizou o setor educacional. Jornal Pequeno. São Luís, Ano XVI, n. 558, p. 1, 27 jan. 1968.

RIBEIRO, Claudett de Jesus. História de uma escola para o povo: projeto João de Barro - Maranhão - 1967/74. São Luís: UFMA/Secretaria Educação - MA, 1985.

O IMPARCIAL. Setecentos professores farão cursos do DAM. São Luís, 06 jan. 1968, ano XXVI, n. 6087, p. 8.

Explosão educacional do maranhão é simpática a técnicos da USAID. São Luís, 15 jan. 1971.

SARNEY, José. Ao povo maranhense. Jornal do Dia. São Luís, 18 dez.1968. p.1

SARNEY, José. Governo e povo. Rio de Janeiro: Artenova, 1970.

Artigo recebido em 12 de fevereiro de 2021. Aprovado em 02 de abril de 2021.

Revista Escritas do Tempo - v. 3, n. 7, jan-abr/2021 - p. -123 